\title{
The iTRAQ-based chloroplast proteomic analysis of Triticum aestivum L. leaves subjected to drought stress and 5- aminolevulinic acid alleviation reveals several proteins involved in the protection of photosynthesis
}

Yuexia Wang ${ }^{1 *}$ D, Xiaoyan $\mathrm{Li}^{1}$, Nana Liư ${ }^{2}$, Shimei Wei ${ }^{1}$, Jianan Wang ${ }^{1}$, Fujun Qin ${ }^{3}$ and Biao Suo ${ }^{4^{*}}$

\begin{abstract}
Backgrounds: The perturbance of chloroplast proteins is a major cause of photosynthesis inhibition under drought stress. The exogenous application of 5-aminolevulinic acid (ALA) mitigates the damage caused by drought stress, protecting plant growth and development, but the regulatory mechanism behind this process remains obscure.

Results: Wheat seedlings were drought treated, and the iTRAQ-based proteomic approach was employed to assess the difference in chloroplast protein content caused by exogenous ALA. A total of 9499 peptides, which could be classified into 2442 protein groups, were identified with $\leq 0.01$ FDR. Moreover, the contents of 87 chloroplast proteins was changed by drought stress alone compared to that of the drought-free control, while the contents of 469 was changed by exogenous ALA application under drought stress compared to that of drought stress alone. The Gene Ontology (GO) annotation and Kyoto Encyclopedia of Genes and Genomes (KEGG) analysis results suggested that the ALA pretreatment adjusted some biological pathways, such as metabolic pathways and pathways involved in photosynthesis and ribosomes, to enhance the drought resistance of chloroplasts. Furthermore, the drought-promoted $\mathrm{H}_{2} \mathrm{O}_{2}$ accumulation and $\mathrm{O}_{2}{ }^{-}$production in chloroplasts were alleviated by the exogenous pretreatment of ALA, while peroxidase (POD) and glutathione peroxidase (GPX) activities were upregulated, which agreed with the chloroplast proteomic data. We suggested that ALA promoted reactive oxygen species (ROS) scavenging in chloroplasts by regulating enzymatic processes.
\end{abstract}

Conclusions: Our results from chloroplast proteomics extend the understanding of the mechanisms employed by exogenous ALA to defend against drought stress in wheat.

Keywords: Chloroplast proteomics, iTRAQ, Drought, Wheat, Reactive oxygen species

\footnotetext{
* Correspondence: yxwang2100@126.com; suobiao1982@126.com

'College of Life Sciences, Henan Agricultural University, No. 63, Nongye Rd. Zhengzhou 450002, Henan Province, China

${ }^{4}$ College of Food Science and Technology, Henan Agricultural University, No. 63, Nongye Rd., Zhengzhou 450002, Henan Province, China

Full list of author information is available at the end of the article
}

(c) The Author(s). 2020 Open Access This article is licensed under a Creative Commons Attribution 4.0 International License, which permits use, sharing, adaptation, distribution and reproduction in any medium or format, as long as you give appropriate credit to the original author(s) and the source, provide a link to the Creative Commons licence, and indicate if changes were made. The images or other third party material in this article are included in the article's Creative Commons licence, unless indicated otherwise in a credit line to the material. If material is not included in the article's Creative Commons licence and your intended use is not permitted by statutory regulation or exceeds the permitted use, you will need to obtain permission directly from the copyright holder. To view a copy of this licence, visit http://creativecommons.org/licenses/by/4.0/ The Creative Commons Public Domain Dedication waiver (http://creativecommons.org/publicdomain/zero/1.0/) applies to the data made available in this article, unless otherwise stated in a credit line to the data. 


\section{Background}

Wheat (Triticum aestivum L.) is one of the most important crops worldwide. However, wheat plants often suffer from drought stress throughout the whole growth stage, which causes serious physiological and biochemical damage, and as a result, the yield is reduced [1]. Plant chloroplasts are one of the most sensitive components to drought stress. Drought causes deteriorative changes in the structure of the subunits within the chloroplast, such as the thylakoid and granum [2], thus disrupting the photosynthetic function of the chloroplast. Under drought conditions, wheat plants cannot sustain a normal performance to provide sufficient photosynthetic products to the plant unless the photosynthetic functions are adequately protected [3].

Sustaining plant chloroplast photosynthetic function under drought stress requires the regulation of chloroplast proteins. In reports from past decades, some proteins that sustain plant chloroplast photosynthetic function under drought stress have been characterized. For example, the content and activity of antioxidant enzymes increase significantly under drought stress, which is aimed at scavenging the reactive oxygen that is produced [4]. Alternative oxidase has been proven to participate in a respiratory electron transport chain pathway that is essential for maintaining photosynthetic performance during drought stress [5]. Limited reports have shown that the translation, phosphorylation, and translocation of chloroplast protein play an important role in the sustainment of photosynthetic function under drought conditions.

However, the functional regulation of chloroplast proteins is inexplicable by using a semiautonomous analytical method. Among the 2000-3000 kinds of proteins in plant chloroplasts, only approximately 100 are assembled in chloroplasts, and the others are encoded by nuclear genes. They are then translated in the cytoplasm and are finally transported to chloroplasts [6]. Therefore, whole leaf-based studies have a limitation in attempting to reveal the function of chloroplast proteins. A proteomic analysis following chloroplast isolation provides a promising approach for elucidating chloroplast-located protein regulation and its relationship with stress resistance $[7,8]$. Until now, the strategy of chloroplast proteomics has been employed to investigate the possible molecular regulatory pathways in response to biotic or abiotic stress in a variety of plants, such as the chlorosis mechanisms of Nicotiana tabacum leaves induced by viral infection [9], the response mechanism of tomato (Solanum lycopersicum L.) to drought stress and recovery [10], and the pathways associated with salt tolerance in Kandelia candel [11]. However, to the best of our knowledge, few studies have reported on the chloroplast proteomic analysis of wheat in response to drought stress, especially when an exogenous regulator is applied.

Growth regulatory substances have long been considered promising for improving the resistance of plants to environmental stress [12]. 5-aminolevulinic acid (ALA) is a precursor of porphyrins in plant chloroplasts [13]. In recent decades, the exogenous application of ALA at low concentrations has exhibited a protective effect on plant development in response to a variety of stresses, such as $\mathrm{NaCl}$ [14], heavy metal [15], waterlogging [16], photodynamical [13], and chilling [17] stresses. Under drought stress, the exogenous application of ALA has been proven to alleviate the damage, which was shown in reports on Kentucky bluegrass [18], alfalfa (Medicago varia Martyn.) [19], Leymus chinensis [20], canola (Brassica napus L.) [21], and wheat [22, 23]. For wheat, the use of ALA is more attractive because this substance was reported to promote growth and alleviate the yield loss caused by dry conditions [24].

Despite the large number of reports on the response of crops to drought, little information is currently available on the plant ALA-induced alleviation mechanism. Because of the predominantly protective effect of ALA against environmental stress, its mechanism has increasingly gained attention. According to the existing evidence, the exogenous application of ALA increases the chlorophyll content, activates antioxidant enzymes, reduces lipid peroxidation of the membrane [13], promotes photosynthesis [15], enhances the tetrapyrrole biosynthetic pathway and proline accumulation [14], improves the metabolism of polyamines [17], regulates nitrogen metabolism, absorption, aggregation and distribution of nutrient ions $[22,25]$, inhibits the microstructural damage in chloroplasts by increasing the proportion of intact thylakoids [26], and regulates the expression of genes [27]. Our previous study showed that ALA pretreatment enhanced the photosynthetic capacity of droughtstressed wheat seedlings [23], but the regulatory mechanism behind this effect is still unknown.

In this study, we used the iTRAQ technique to identify differentially abundant proteins in the chloroplasts of wheat seedlings under drought stress that were pretreated with exogenous ALA. The aim of this study was to explore the major proteins and enzymes involved in chloroplast regulation in response to drought stress. We also provided a theoretical basis for understanding the regulatory pathways of exogenous ALA when the plant is subjected to drought stress.

\section{Results}

Effects of exogenous ALA on the physiological response of wheat under drought stress

In this study, the mitigative effect of exogenous ALA on the drought response of wheat was evaluated by measuring the physiological traits of wheat. As shown in Fig. 1, 


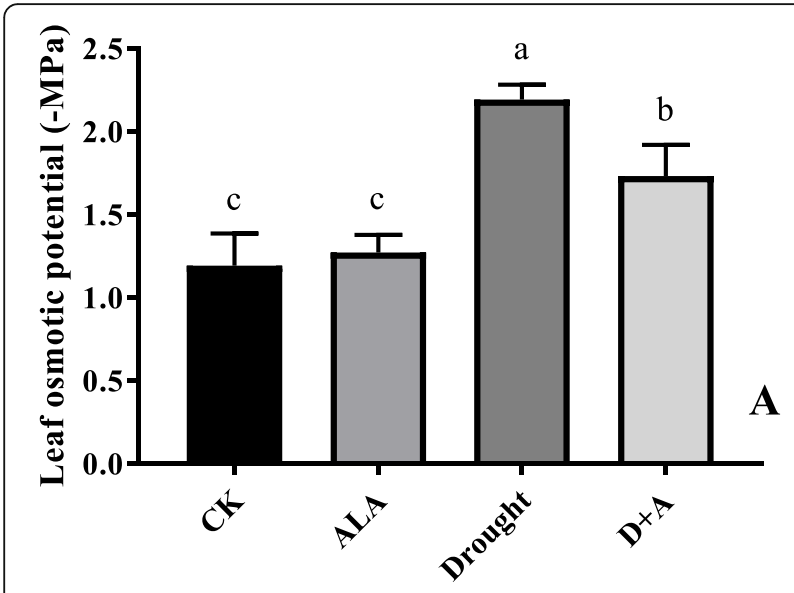

Treatment

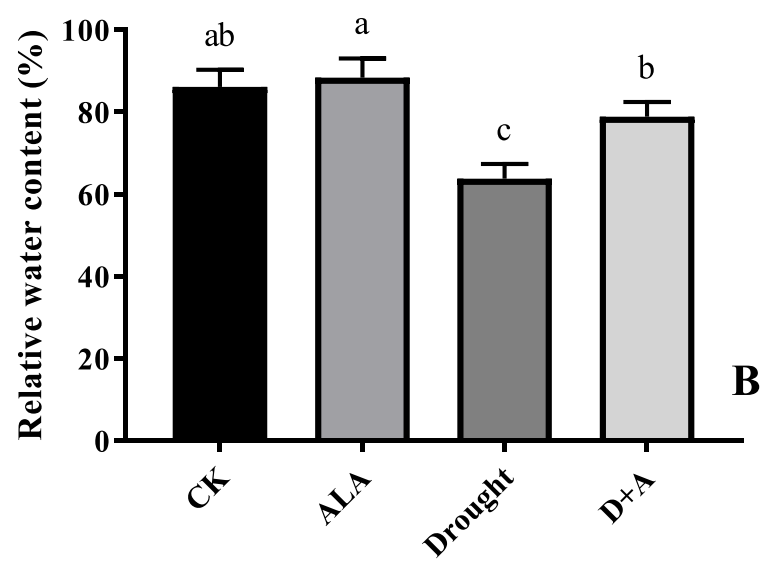

Treatment

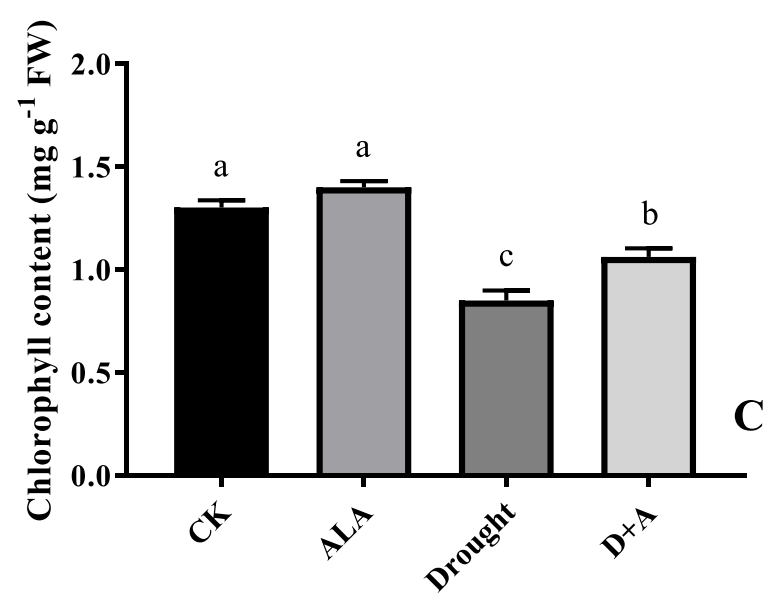

Treatment
Fig. 1 Effects of ALA on leaf osmotic potential (a), relative water content (b), and chlorophyll content (c) in wheat seedlings under drought stress. Each value is the mean of three replicates, and the vertical bars indicate the standard errors (SE). CK, treated with $0 \mathrm{mg} \mathrm{L}^{-1} \mathrm{ALA}$ + distilled water; ALA, treated with $100 \mathrm{mg} \mathrm{L}^{-1}$ ALA and distilled water; drought, treated with $0 \mathrm{mg} \mathrm{L}^{-1}$ ALA without distilled water; $\mathrm{D}+\mathrm{A}$, treated with $100 \mathrm{mg}$ $\mathrm{L}^{-1} \mathrm{ALA}$ without distilled water. The wheat plants underwent drought stress $3 \mathrm{~d}$ after pretreatment with or without ALA

drought stress significantly increased the leaf osmotic potential, but decreased the RWC and chlorophyll contents $(P<0.05)$. However, when exogenous ALA was pre-treated on wheat leaves, the osmotic potential decreased by $21 \%$ compared to that under drought stress alone, while the RWC and chlorophyll contents increased by 24 and $25 \%$, respectively. These three indicators formed the basis of the physiological response analysis, which proposed that the exogenous ALA could alleviate the response due to drought stress. Therefore, leaf samples obtained under different treatments, which were assumed to have different chloroplast proteomes, were used for the proteomics analysis.

\section{Primary data analysis and protein identification}

The chloroplast proteomics were analyzed in three biological triplicates of leaves of wheat seedlings under four treatments. After LC-MS determination and bioinformatic analysis, a total of 9499 peptides were identified with $\leq 0.01$ FDR (Supplementary Table 1) and could be classified into 2442 protein groups (Supplementary Table 2). Principal component analysis (PCA) showed the similarities or difference of samples among CK (normal watering), drought (without water supplement), ALA (normal watering with exogenous ALA application), and D + A (without water supplement but with exogenous ALA application) (Supplementary Figure 1). The total variances in the proteins of the four samples were $44.4 \%$ (PC1) and 20\% (PC2) with an acceptable separation indicated by the four different clusters. The $\mathrm{D}+\mathrm{A}$ treated sample were the farthest to the CK sample compare with ALA and drought treated ones. This indicated that exogenous ALA application under drought stress could cause most serious proteomic changes, compared to drought or ALA treated alone.

The differentially abundant chloroplast proteins (DACPs) were identified between the ALA treatment and the CK, aiming to understand the possible influence of ALA pretreatment on chloroplast protein accumulation under normal watering conditions. The DACPs between the drought treatment and CK were identified to understand the effect of drought stress on protein accumulation in chloroplasts. The comparison between the ALA plus drought treatment and drought alone was aimed at understanding the possible alleviation mechanism of exogenous ALA on droughtinduced damage. As shown in Fig. 2 and Supplementary 


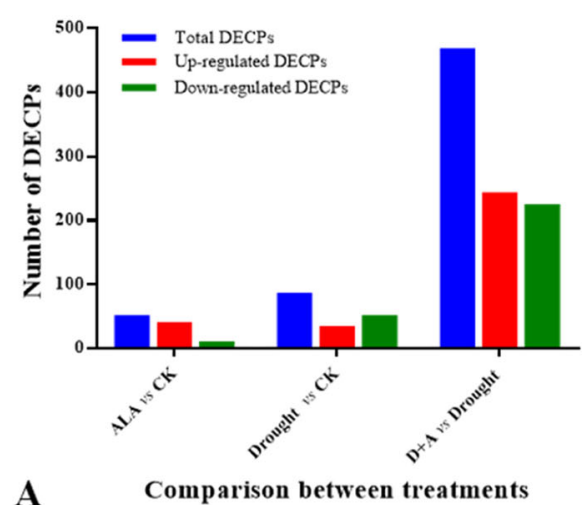

A

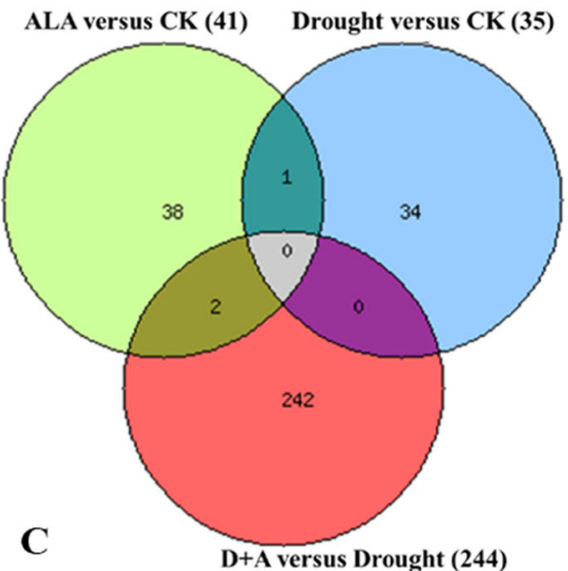

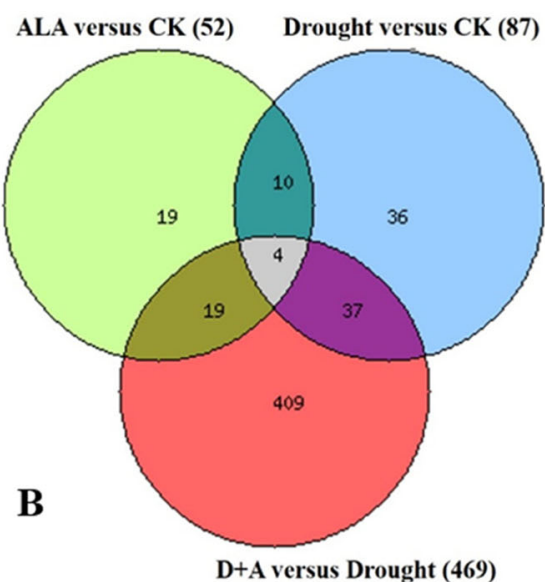

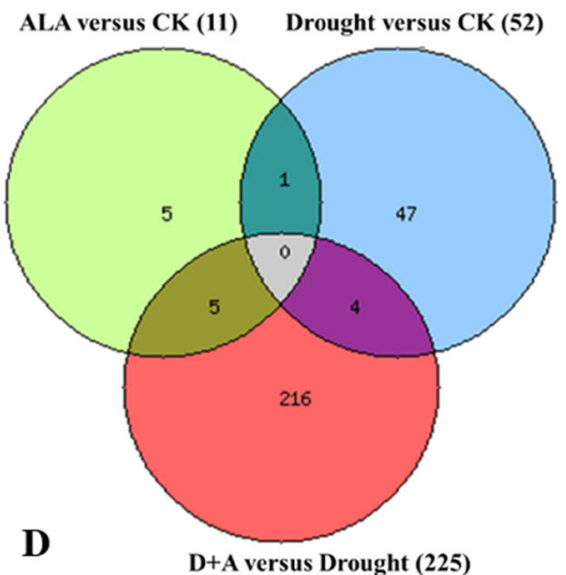

Fig. 2 Venn diagrams of the differentially abundant chloroplast proteins (DACPs) in wheat leaves between different treatments. a Total DACPs; b Upregulated DACPs; c Downregulated DACPs. CK, treated with $0 \mathrm{mg} \mathrm{L}^{-1} \mathrm{ALA}+$ distilled water; ALA, treated with $100 \mathrm{mg} \mathrm{L}^{-1}$ ALA and distilled water; drought, treated with $0 \mathrm{mg} \mathrm{L}^{-1}$ ALA without distilled water; $\mathrm{D}+\mathrm{A}$, treated with $100 \mathrm{mg} \mathrm{L}^{-1} \mathrm{ALA}$ without distilled water. The wheat plants underwent drought stress $3 \mathrm{~d}$ after pretreatment with or without ALA

Table 2, 52, 87, and 469 DACPs were identified between the treatments of ALA and CK, drought and CK, and ALA plus drought and drought alone, respectively. Among the DACPs, 41, 35, and 244 were upregulated, while 11,52, and 225 were downregulated. The identified proteins were notably different in the ALA, drought alone, and ALA plus drought treatments compared to the control treatment (Fig. 3). These identified proteins were filtered to verify whether the changes in protein abundance are significant. This was based on a fold change $\geq 1.5$ or $\leq 0.667$ and $p \leq 0.05$. The results revealed that the ALA pretreatment under drought stress had a greater influence on chloroplast protein accumulation than did the ALA and drought alone treatments.

qRT-PCR assays were performed to validate the gene expression patterns of six randomly selected DACPs. For each DACP, the gene transcriptions were evaluated under ALA, drought, and D + A treatments, respectively, using the $\mathrm{CK}$ as reference sample. A subset of 18 transcriptions was tested to confirm the proteomic results. As shown in Supplementary Figure 2, a strong positive correlation was observed $\left(R^{2}=0.78\right)$, confirming the validity of the proteomic data used in this study.

\section{Functional categorization of the DACPs}

To understand the protein functions associated with the DACPs under ALA pretreatment and drought stress, GO analysis was performed using BLAST2GO software. The GO functional categorization generated 327 annotations from the 52 DACPs between ALA-pretreated only wheat seedlings and CK (Fig. 4a). In that study, 116, 39, and 172 annotations could be classified as the first level classifications of biological processes, molecular functions, and cellular components, respectively. Among the biological process classifications, 24 and 21 DACPs were classified into the categories of cellular processes (GO: 0009987) and metabolic processes (GO:0008152), respectively. In the cellular component classification, the 


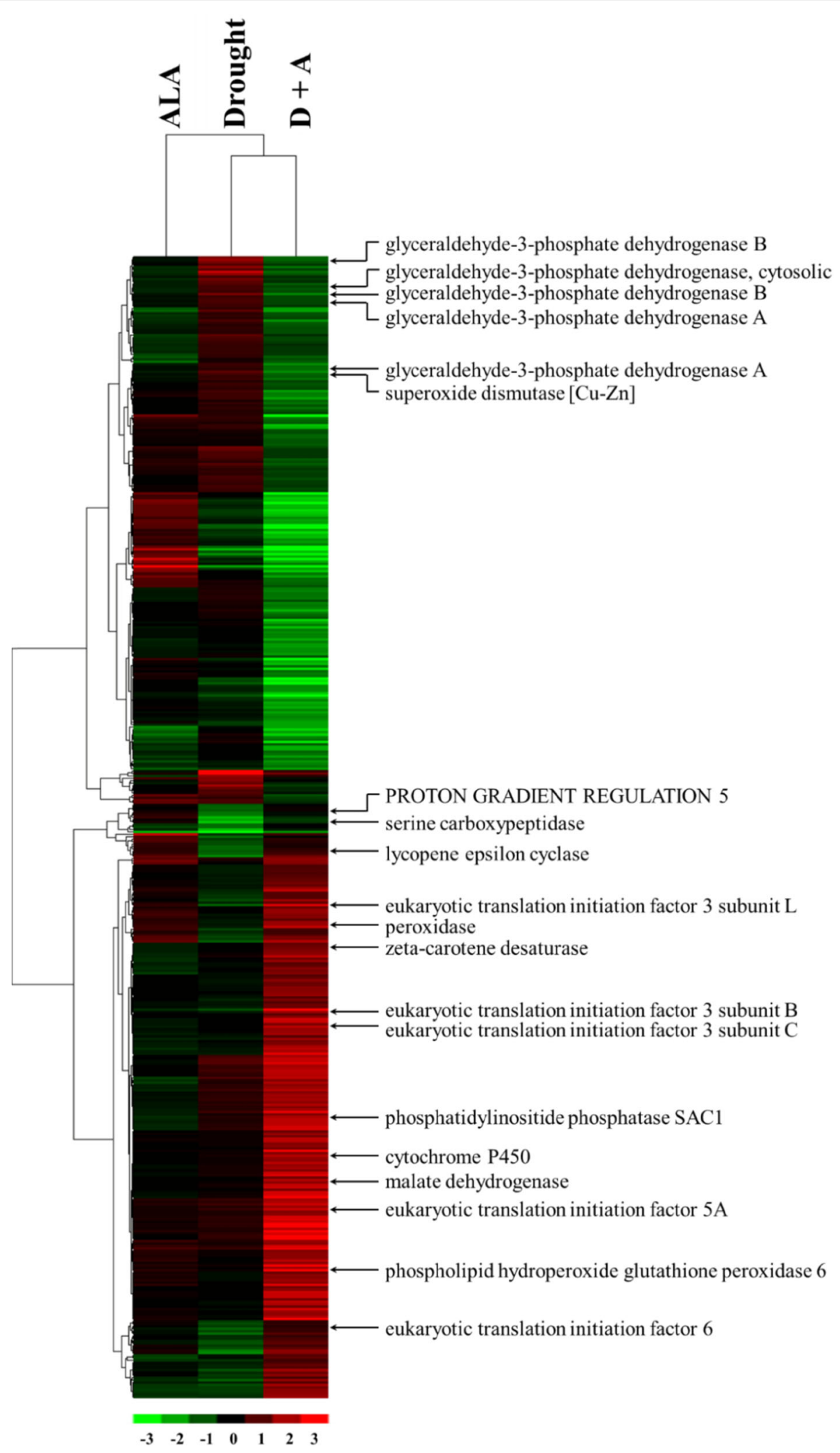

Fig. 3 (See legend on next page.) 
(See figure on previous page.)

Fig. 3 Hierarchical clustering analysis of 469 differentially abundant chloroplast proteins (DACPs) in D + A versus drought. The content patterns of the proteins were hierarchically clustered based on the ratio as a $\log _{2}$ scale. Each row in the color heat map indicates a single chloroplast protein extracted from ALA (treated with $100 \mathrm{mg} \mathrm{L}^{-1}$ ALA and distilled water), drought (treated with $0 \mathrm{mg} \mathrm{L}^{-1} \mathrm{ALA}$ without distilled water), and D + A (treated with $100 \mathrm{mg} \mathrm{L}^{-1} \mathrm{ALA}$ without distilled water). The sample from plants treated with distilled water was used as a reference control. The red-colored clusters represent upregulated proteins, and the green-colored clusters represent downregulated proteins

two main categories were cell part (GO:0044464) and cell (GO:0005623). In the molecular function classification, the most common category was binding (GO: 0005488).

The GO functional categorization generated 603 annotations from the $87 \mathrm{DACPs}$ between drought-treated only seedlings and CK (Fig. 4b). In that study, 246, 282, and 75 annotations could be classified as the first level classifications of biological processes, cellular components, and molecular functions, respectively. In the biological process classification, 52 and 49 DACPs were classified into the categories of metabolic processes (GO: 0008152) and cellular processes (GO:0009987). In the cellular component classification, the 56 DACPs were classified into both the cell part (GO:0044464) and cell (GO:0005623) categories. Among the molecular function classifications, 33 and 29 DACPs were classified into the categories of binding (GO:0005488) and catalytic activity (GO:0003824).

Regarding GO enrichment for the DACPs in D + A vs. drought alone, 3366 annotations were generated from the 469 DACPs (Fig. 4c). The top five enriched GO terms in the biological process classification were metabolic processes (GO:0008152), cellular processes (GO: 0009987), single-organism processes (GO:0044699), cellular component organization (GO:0071840), and biological regulation (GO:0065007). For the cellular component classification, the top five enriched GO terms were cell (GO:0005623), cell part (GO:0044464), organelle (GO:0043226), organelle part (GO:0044422), and membrane (GO:0016020). The most enriched terms within the molecular function classification were binding (GO:0005488) and catalytic activity (GO:0003824).

\section{KEGG pathway analysis of the DACPs}

The functions of the DACPs between the different treatments were further analyzed by the KEGG pathway annotation method (Fig. 5). The 469 DACPs between the $\mathrm{D}+\mathrm{A}$ and drought-treated seedlings were subcategorized into 84 KEGG classifications. "Metabolic pathways" was the most represented pathway, followed by "biosynthesis of secondary metabolites", "carbon metabolism", "ribosome", and "photosynthesis" (Fig. 5a). "Metabolic pathways" was also the most represented pathway in ALA versus CK and drought versus CK (Fig. $5 b$ and c). In ALA versus CK, the four most represented pathways subcategorized by 52 DACPs were metabolic pathways, photosynthesis - antenna proteins, photosynthesis, and ribosomes. The four most represented pathways subcategorized by the 87 DACPs of drought versus CK were metabolic pathways, biosynthesis of secondary metabolites, carbon metabolism, and photosynthesis. The KEGG pathway analysis results indicated that drought stress and exogenous ALA application mainly influence the pathways of metabolites and photosynthesis.

\section{Protein-protein interactions of DACPs}

The DACPs were analyzed using the STRING online search tool, and the PPIs with a score higher than 0.7 were used to build an interaction network by employing Cytoscape software. As shown in Fig. 6, the PPI network of $\mathrm{D}+\mathrm{A}$ vs. drought alone contained 519 edges, which is higher than the expected number (423). The excessive edge number denoted that the proteins have more PPIs, compared to what would be expected for a random set of proteins of similar size drawn from the genome. The results suggested that the DACPs are at least partially biologically connected as a group.

\section{Discussion}

Plant chloroplast is essential for the sustainment of photosynthetic function under drought condition, which can be attributed to the regulation of protein content. A detailed knowledge of the changes in chloroplast proteins in response to drought is essential to understand the mechanisms underlying stress adaptation. In this study, we have focused on the chloroplast response to drought stress with or without ALA pretreatment and evaluated its possible contribution to drought resistance of photosynthesis.

According to the proteomic data, a cytochrome P450 71A9-like protein (A0A1D5YKA1) was upregulated by ALA pretreatment under drought stress. In Arabidopsis, cytochrome P450 mediates the Baeyer-Villiger oxidation of castasterone to brassinolide in brassinosteroid biosynthesis [28]. Brassinosteroid is a polyhydroxylated steroidal plant hormone that plays a pivotal role in regulating various plant growth and development processes. Many studies have already claimed that brassinosteroids improve growth and yield in agricultural systems under various stress conditions, including drought [29]. The novelty of the accumulation of cytochrome P450 in present result was that, the pretreatment with ALA could enhance drought resistance by 


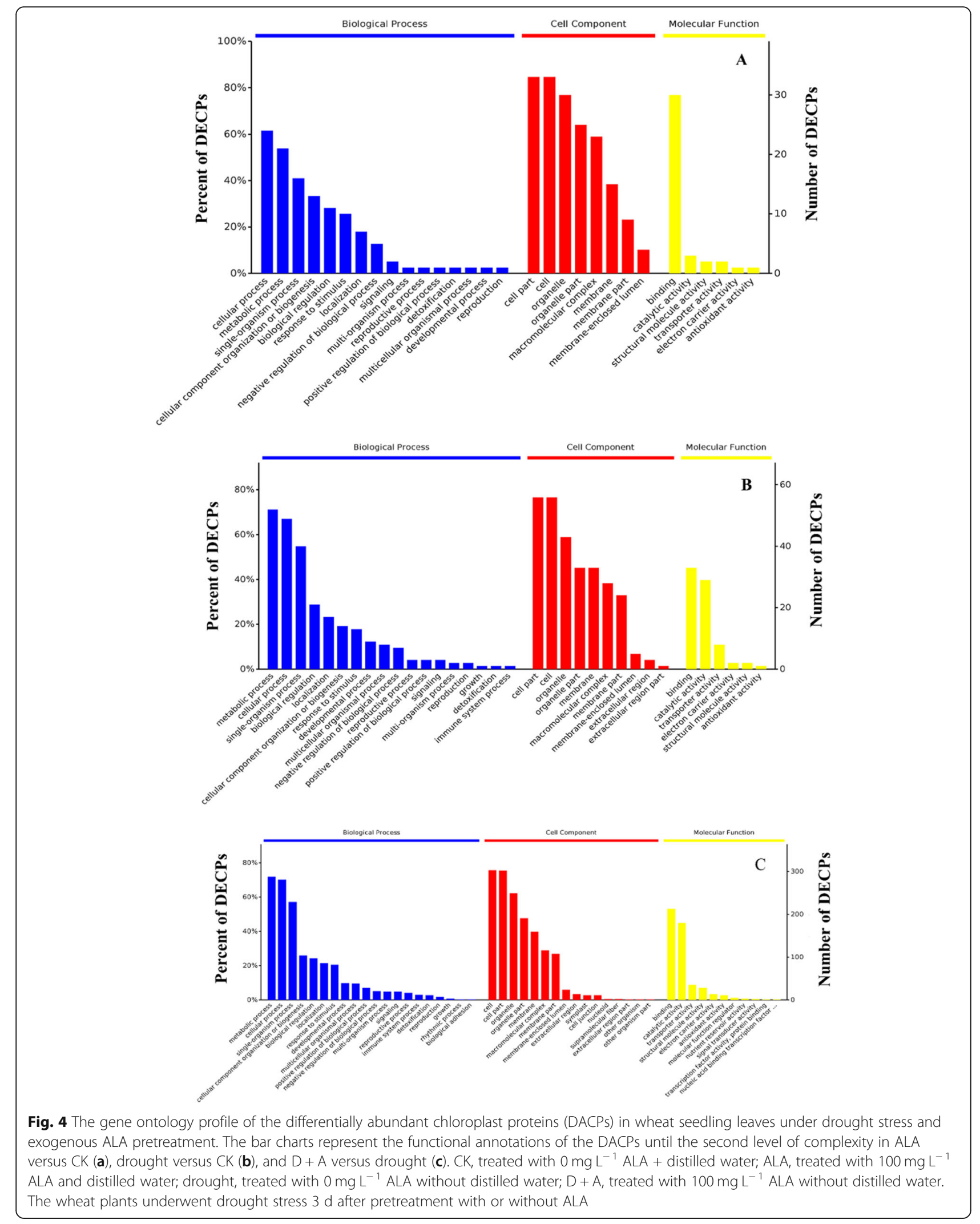


promoting brassinosteroid biosynthesis, possibly contributing to sustaining the yield of wheat under drought stress [24].

When plant is suffering from drought stress, the carbon/nitrogen ratio is normally altered and induces nutrient mobilization because of the $\mathrm{CO}_{2}$ limitation. In the ALA-pretreated seedlings under drought stress, a 1.7fold increase was observed for malate dehydrogenase
(MDH) (A0A1D5YPG2) compared to that of seedling under drought stress alone. $\mathrm{MDH}$ plays a key role in the regulation of the carbon/nitrogen ratio by participating in the Krebs cycle. When $\mathrm{CO}_{2}$ assimilation is restricted under environmental stresses, the accumulation of $\mathrm{MDH}$ in chloroplasts accompanies with the regeneration of the electron acceptor $\mathrm{NADP}^{+}$[30], which is beneficial for the short-term adjustment of the stromal NADPH redox

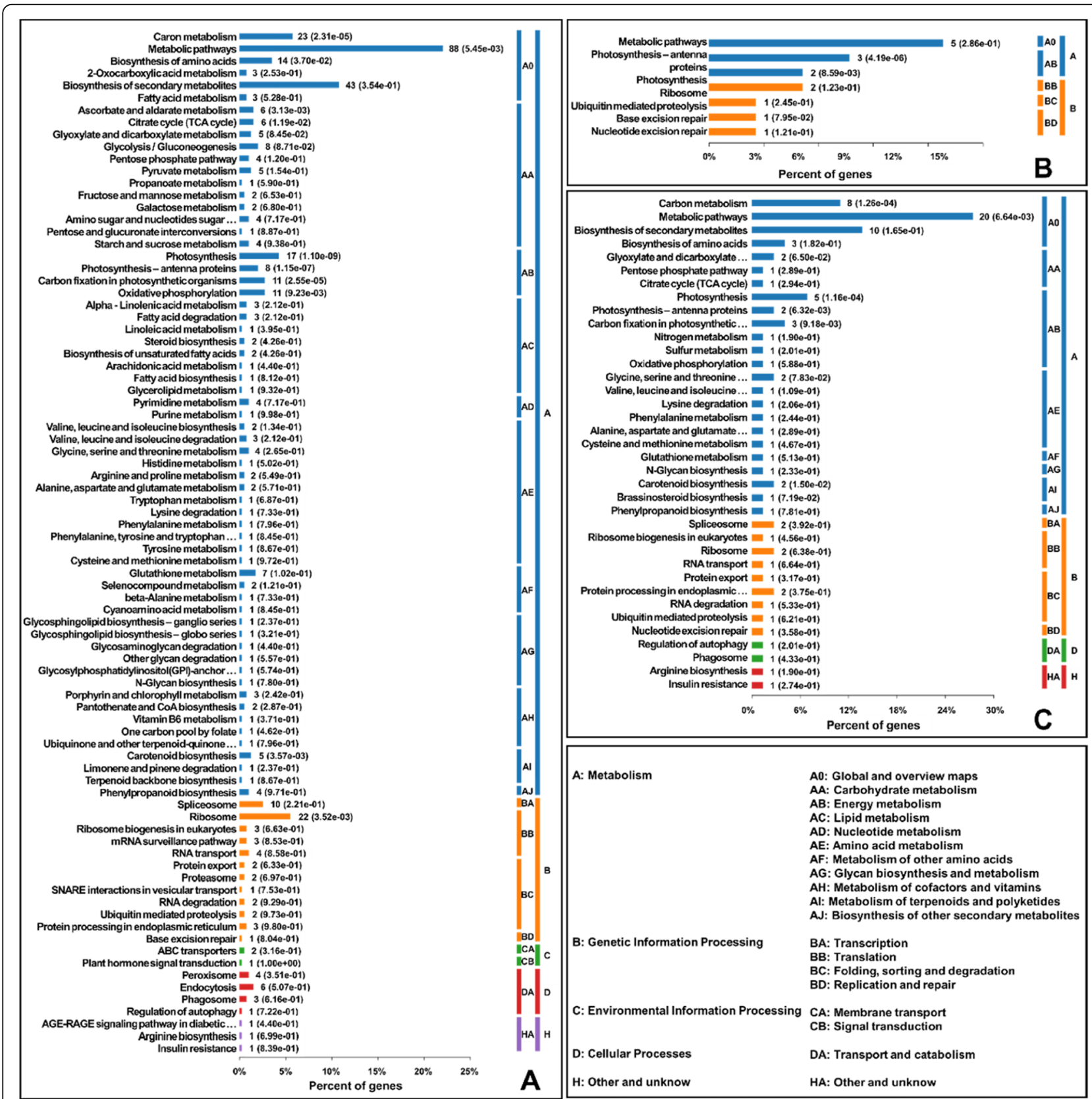

Fig. 5 Enriched KEGG pathways of differentially abundant chloroplast proteins (DACPs) in wheat seedling leaves under drought stress and exogenous ALA pretreatment. a D + A versus D; $\mathbf{b}$ ALA versus CK; and $\mathbf{c}$, drought versus CK. The number of involved proteins in a specific pathway and corresponding $p$-values are shown on the right side of the column. CK, treated with $0 \mathrm{mg} \mathrm{L}^{-1} \mathrm{ALA}+$ distilled water; ALA, treated with $100 \mathrm{mg} \mathrm{L}^{-1} \mathrm{ALA}$ and distilled water; drought, treated with $0 \mathrm{mg} \mathrm{L}^{-1} \mathrm{ALA}$ without distilled water; $\mathrm{D}+\mathrm{A}$, treated with $100 \mathrm{mg} \mathrm{L}^{-1}$ ALA without distilled water 
stage [31]. The observed downregulation of the biosynthesis of amino acid-related proteins by ALA pretreatment is suggestive of stimulating the alternative catabolic pathways to generate energy in need to preserve its existing energy [32].

It is known that there are at least two photosynthetic cyclic electron transport (CET) pathways in most C3 plants: the $\mathrm{NAD}(\mathrm{P}) \mathrm{H}$ dehydrogenase (NDH)-dependent pathway and the proton gradient regulation5 (PGR5) (H9C8A5)-dependent pathway [33]. In the present study, when wheat seedlings were pretreated with ALA, $\mathrm{NAD}(\mathrm{P}) \mathrm{H}$ dehydrogenase was significantly downregulated under drought stress. However, the key protein in the ferredoxin-dependent CET pathway, proton gradient regulation 5 (PGR5), was downregulated under drought stress. Interestingly, PGR5 accumulated significantly with the pretreatment of ALA. In addition, ribulose bisphosphate carboxylase (small and large chain) was downregulated in the ALA-pretreated wheat seedlings, but ribulose bisphosphate carboxylase/oxygenase activase showed a 1.9-fold increase. In both Arabidopsis thaliana and Chlamydomonas reinhardtii, PGR5mediated CEF and showed that PGR5/PGRL1-Fd CEF functions in accordance with an ATP/redox control model [33]. The Arabidopsis plants overexpressing PGR5 exhibited better survival when exposed to high light and drought stress than did the wild-type plants [34]. Therefore, the present proteomic data indicated that exogenous ALA application protected wheat seedlings under drought stress by activating a PGR5dependent pathway.

The serine carboxypeptidase-like protein family is located on the cytomembrane and has been shown to play

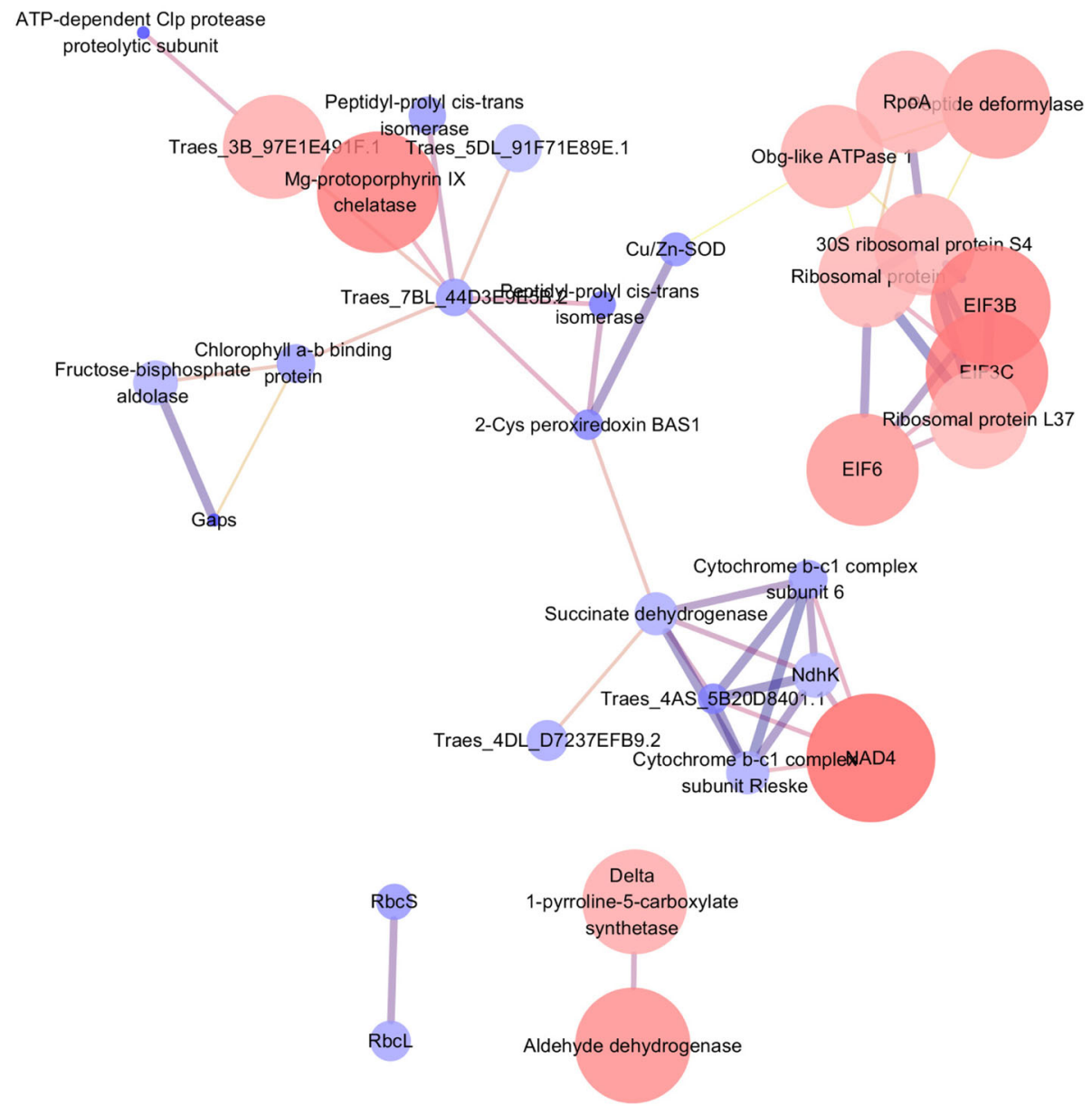

Fig. 6 Protein-protein interaction networks of differentially abundant chloroplast proteins (DACPs) of wheat seedlings treated with $100 \mathrm{mg} \mathrm{L}^{-1}$ ALA without distilled water $(D+A)$ compared to that treated by drought stress alone. Proteins are indicated with nodes, and interactions between proteins are represented by edges. The edge colors indicate the combined score. The node colors represent upregulated protein (red) or downregulated protein (blue), and the size of node also indicates the change in the level of protein expression. Nad4, NADH-ubiquinone oxidoreductase chain 4; NdhK, NAD(P)H-quinone oxidoreductase subunit K; RpoA, DNA-directed RNA polymerase subunit alpha; RbcL, Ribulose bisphosphate carboxylase large chain; RbcS, Ribulose bisphosphate carboxylase small chain; Cu/Zn-SOD, superoxide dismutase Cu/Zn isoform; Gaps, glyceraldehyde-3-phosphate dehydrogenase 
a key role in plant growth, development and stress responses [35, 36]. These proteins in rice leaves was significantly accumulated after treatments with benzothiadiazole, salicylic acid, jasmonic acid and 1-amino cyclopropane-1carboxylic acid, etc. The over-abundant plants also showed an increased tolerance to oxidative stress and upregulated expression of oxidative stress-related genes [37]. The present proteomic data showed that serine carboxypeptidase (A0A1D6ANR8) was downregulated under drought stress alone but accumulated by 2.1-fold when ALA was applied prior to drought stress. The upregulation effect of exogenous ALA was not significantly shown in the drought-free condition. The results suggested that serine carboxypeptidase may be involved in the regulation of exogenous ALA to protect against drought stress.

A number of recessive resistance genes have been shown to encode eukaryotic translation initiation factors (EIFs). A core set of EIFs is conserved to facilitate the assembly of a translation-competent ribosome at the initiation codon of a mRNA [38]. An increasing number of studies have shown that plant EIFs play roles in stress resistance, such as eiF (iso) $4 E$ in B. rapa [39] and eif $2 B$ beta in B. juncea [40] in response to TuMV. In the present study, two isoforms of EIF, 6 and $3 \mathrm{~L}$, were downregulated in response to drought stress, while five isoforms of EIF, 5A, 6, 3B, 3C, and $3 \mathrm{~L}$, accumulated in the drought-stressed wheat seedlings pretreated with exogenous ALA. Eukaryotic translation initiation is a highly regulated and complex stage of gene translation, which requires the action of at least 13 core initiation factors and five auxiliary factors [38, 41]. Among the EIFs, EIF $5 \mathrm{~A}$ is a highly conserved protein in all eukaryotic organisms, and the mutant analysis in Arabidopsis has demonstrated that it influences $\mathrm{Cd}$ sensitivity by affecting $\mathrm{Cd}$ uptake, accumulation, and detoxification [42]. The accumulation of these wheat EIFs under drought stress represents new targets and mechanisms for the protective strategies of the exogenous application of ALA. It is known that oxidative stress often occurs as a result of drought stress. As shown in Fig. $7 \mathrm{a}$ and b, the $\mathrm{H}_{2} \mathrm{O}_{2}$ content and $\mathrm{O}_{2}{ }^{-}$production rate in the wheat chloroplasts both increased significantly in response to drought stress $(P<0.01)$. The ALA pretreatment alleviated the damage caused by reactive oxygen species (ROS) in chloroplasts, as shown by the fact that both the $\mathrm{H}_{2} \mathrm{O}_{2}$ content and $\mathrm{O}_{2}{ }^{-}$production rate noticeable decreased, although they were still higher than those of the drought-free seedlings. In recent decades, studies have shown that the chemical nature of reactive oxygen species (ROS) indicates that they are not only potentially harmful to plant cells but that they also act as a second messenger in signal transduction in response to
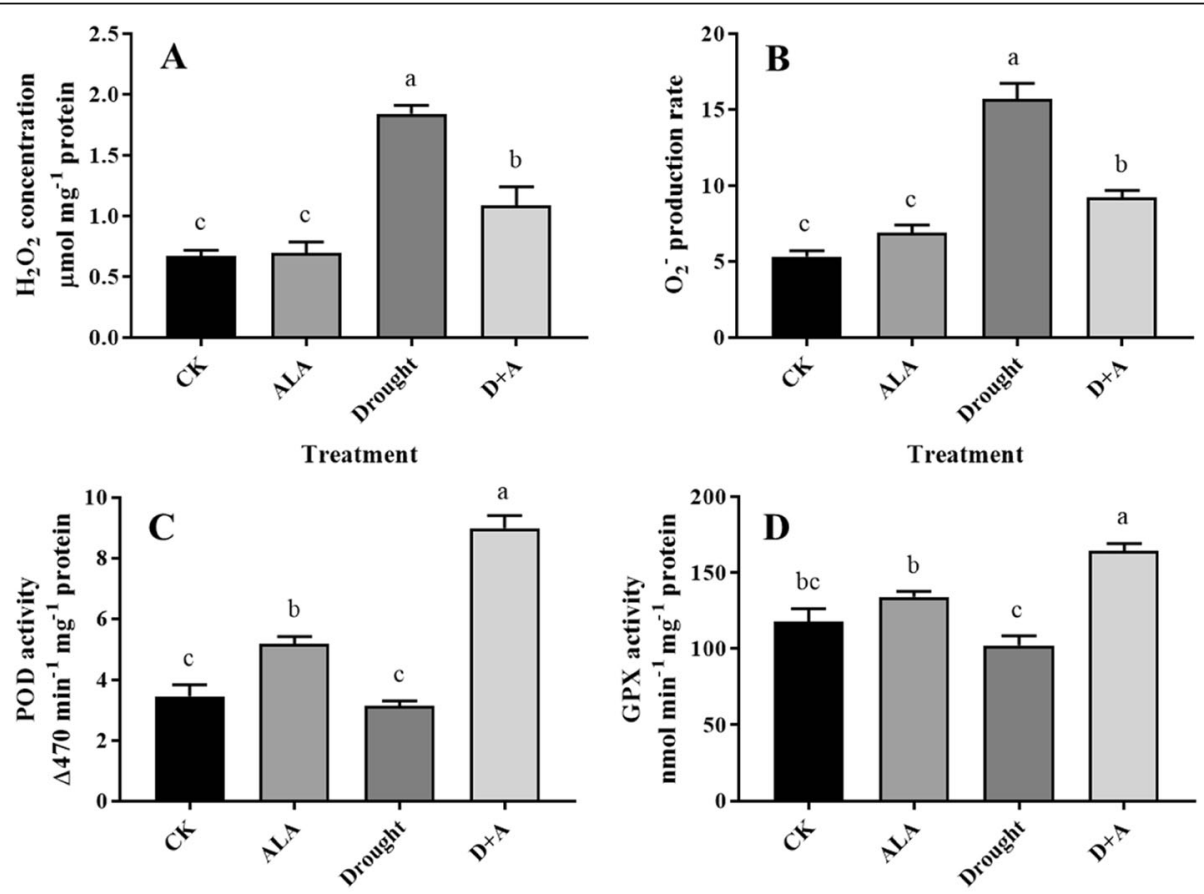

Treatment

Treatment

Fig. 7 Effects of exogenous ALA on the $\mathrm{H}_{2} \mathrm{O}_{2}$ concentration (a), $\mathrm{O}_{2}^{-}$production rate (b), POD (c) and GPX (d) activities in chloroplasts in leaves of wheat seedlings exposed to drought stress. CK, treated with $0 \mathrm{mg} \mathrm{L}^{-1} \mathrm{ALA}+$ distilled water; ALA, treated with $100 \mathrm{mg} \mathrm{L}^{-1} \mathrm{ALA}$ and distilled water; drought, treated with $0 \mathrm{mg} \mathrm{L}^{-1} \mathrm{ALA}$ without distilled water; $\mathrm{D}+\mathrm{A}$, treated with $100 \mathrm{mg} \mathrm{L}^{-1} \mathrm{ALA}$ without distilled water. Error bars represent SD values $(n=3)$. Different letters indicate significant differences among the treatments $(P<0.01)$ 
environmental stress [43]. According to the present chloroplast proteomic data, phospholipid hydroperoxide glutathione peroxidase (GPX) (A0A1D5U2X7) and peroxidase (POD) (A0A1D6BMX2) were 1.7- and 2.2-fold upregulated by ALA pretreatment, respectively, compared to those of drought alone. The proteomic data were coincident with the results from the enzymatic analysis of GPX and POD in the wheat chloroplasts (Fig. $7 \mathrm{c}$ and $\mathrm{d}$ ). However, the superoxide dismutase $\mathrm{Cu} / \mathrm{Zn}$ isoform $(\mathrm{Cu} / \mathrm{Zn}$-SOD) (C3VQ50) was 0.5-fold downregulated, and catalase (CAT) (A0A0A7MA13) did not show a significant change $(P<0.05)$ in either drought alone or ALA plus the drought treatment. The results could be attributed to the fact that $\mathrm{Cu} / \mathrm{Zn}$-SOD mainly functions as a ROS scavenger in the cytoplast and only scavenges ROS a little in chloroplasts [44]. GPX catalyzes the reduction of $\mathrm{H}_{2} \mathrm{O}_{2}$, organic hydroperoxide, and lipid peroxides using glutathione (GSH), thioredoxin (TRX) and/or other reducing equivalents and is generally considered to be the main line of enzymatic defense against oxidative membrane damage [45-47]. GPX has been proven to function as both a redox transducer and an ROS scavenger in abscisic acid and drought stress response in Arabidopsis [48]. The over-accumulation of GPX in the chloroplasts of transgenic tobacco removed unsaturated fatty acid hydroperoxides that were generated in cellular membranes under stress conditions, leading to the maintenance of membrane integrity and increased tolerance to oxidative stress caused by various stress conditions [49]. PODs are primarily localized in cell walls and vacuoles [50], but a recent report has shown that PODs are also present in chloroplasts [51]. POD catalyzes oxidative reactions by converting hydrogen peroxide $\left(\mathrm{H}_{2} \mathrm{O}_{2}\right)$ to $\mathrm{H}_{2} \mathrm{O}$, while a substrate is being oxidized, thus playing an important role in drought resistance [52]. Phosphoinositide phosphatase SAC8 is also involved in reducing the accumulation of ROS [53]. In our study, the proteomic data showed that the exogenous pretreatment of ALA increased the level of the phosphoinositide phosphatase SAC8 isoform SAC1 (A0A1D5SX72) in wheat chloroplasts, which was similar to the result of NaHS pretreatment in drought-stressed wheat seedlings [54]. In the present study, the exogenous ALA-triggered accumulations of GPX, POD, and phosphoinositide phosphatase SAC1 indicated were ROS scavengers when the wheat plants were suffering from drought stress.

In higher plant leaves, there are three kind of glyceraldehyde-3-phosphate dehydrogenase (Gaps) that participate in the environmental stress response by catalyzing key steps in energy and reducing power partitioning in cells; GapA and GapB are in chloroplasts, while GapC is in the cytoplasm [55, 56]. According to the proteomic data, GapB (A0A1D5XJY0, A0A1D5YL67) accumulated when the wheat seedlings were subjected to drought stress alone, while GapA (A0A1D5T798, A0A1D5TTT4), GapB, and GapC (A0A1D6C9L9) all showed significant downregulation when exogenous ALA was used as a pretreatment. The accumulation of Gap benefits the transduction of the ROS hydrogen peroxide $\left(\mathrm{H}_{2} \mathrm{O}_{2}\right)$ signal in response to drought stress, and a knockout of Gap decreases stomatal sensitivity to ABA and renders plants less responsive to water deficits than the wild type [57]. When wheat seedlings were pretreated with ALA, the downregulation of Gaps was coordinated with a lower content of $\mathrm{H}_{2} \mathrm{O}_{2}$ in a previous report [23], which was most likely associated with the accumulation of the ROS scavengers GPX and POD.

There are also some nonenzymatic molecular antioxidants that participate in ROS scavenging, including ascorbate, $\alpha$-tocopherol, carotenoids, and glutathione [58]. The lycopene epsilon cyclase negatively regulates carotenoid synthesis by the $\beta$-branch-specific pathway during the stress response [59]. The lycopene epsilon cyclase (C1IP74) was down represented in response to drought stress, which contributed to sustaining the content of carotenoids at a certain level to scavenge ROS in chloroplasts [60]. The exogenous pretreatment of ALA accumulated lycopene epsilon cyclase in chloroplasts under drought stress, implying that a high carotenoid content was not yet necessary because of the lower ROS production and higher chlorophyll content when the drought-stressed wheat seedlings were pre-treated with exogenous ALA than when they were treated with drought stress alone. Zeta-carotene desaturase (A0A1D5U7A6) is another chloroplast protein that is essential for carotenoid biosynthesis. It was upregulated in the ALA-pretreated wheat seedlings compared to in the seedlings under drought stress alone. Furthermore, the accumulation of zeta-carotene desaturase plays an important role in chlorophyll biosynthesis, coloration, chloroplast biogenesis, and PSII capacity [61]. The results suggested that pretreatment with ALA participated in the nonenzymatic antioxidant process by regulating carotenoid biosynthesis-related proteins.

Among the identified DACPs, there were some nonchloroplastic proteins identified and showed significant changes under treatments. For example, the histones $\mathrm{H} 2 \mathrm{~A}, \mathrm{H} 2 \mathrm{~B}, \mathrm{H} 3$, and $\mathrm{H} 4$ were all down-regulated by the exogenous application of ALA under drought stress, which were coincident with results reported in rice under cold stress [62]. The non-chloroplast protein contaminations should be attributed to the Percoll-based chloroplast purification protocol that cannot fully exclude cross-contaminations originating from other plastids and cell compartments, even it has been well established $[7,8]$. Histones are prone to reversible posttranslational modifications such as phosphorylation, 
ubiquitination, acetylation, methylation, and glycosylation, which allow the proteins to respond flexibly to stimuli [63]. They are DNA-binding proteins of nucleoids or nucleomorph, while may possibly be posttranslationally modified and perform the role in chloroplasts $[64,65]$.

\section{Conclusions}

In summary, an iTRAQ-based proteomics approach was employed to assess the changes in chloroplast protein content caused by exogenous ALA in wheat leaves under drought stress. A total of 9499 peptides were identified with $\leq 0.01$ FDR and could be classified into 2442 protein groups. Moreover, the contents of 87 chloroplast proteins were changed by drought stress alone, while 469 were changed by exogenous ALA application under drought stress. The results suggest that ALA pretreatment changed some biological pathways, such as metabolic pathways and pathways involved in photosynthesis and ribosomes, to enhance the drought resistance of chloroplasts. Moreover, ALA promoted ROS scavenging by regulating enzymatic processes. Our results from chloroplast proteomics extend the understanding of the mechanisms employed by exogenous ALA to defend against drought stress in wheat.

\section{Methods}

\section{Plant materials and treatments}

Seeds of the wheat cultivar Aikang-58 with uniform sizes were selected and surface sterilized using $5 \% \mathrm{H}_{2} \mathrm{O}_{2}$ for 3 min. Aikang-58 was commercially acquired from Henan New Agricultural Seed Industry co., LTD. The wheat cultivar was selected as the material because it is a drought-tolerant cultivar that has been planted in a large area in northern China. After $12 \mathrm{~h}$ of being immersed in tap water, the identical and just germinated seeds were subjected to a subsequent $48 \mathrm{~h}$ of pregermination on a double layer of moist filter paper. The identical and germinated seeds were then transferred to a plastic flower pot (length $6.8 \mathrm{~cm}$, width $6.8 \mathrm{~cm}$, and height $7.1 \mathrm{~cm}$ ) with $90 \mathrm{~g}$ of nutrient soil. The growth chamber was manually controlled under a $14 \mathrm{~h} / 10 \mathrm{~h}$ (light/dark) photoperiod at $300 \mu \mathrm{mol} \mathrm{m}{ }^{-2} \mathrm{~s}^{-1}$ of photosynthetic photon flux density (PPFD) provided by fluorescent lamps. The light period was set from $7 \mathrm{AM}$ to $9 \mathrm{PM}$ every day. The ambient environmental temperature and relative humidity were controlled at $25^{\circ} \mathrm{C} / 22^{\circ} \mathrm{C}$ (day/night) and $75 \sim 85 \%$, respectively. The wheat seedlings were watered with 400 $\mathrm{mL}$ of water every $2 \mathrm{~d}$ until two leaves were fully expanded, and $100 \mathrm{mg} \mathrm{L}^{-1}$ ALA was foliar applied according to our previous evaluation results [23]. Three days after ALA treatments, the seedlings were subjected to drought stress by a cessation of watering, while the control group was watered as normal. The treatment combinations were set as follows: (1) $\mathrm{CK}, 0 \mathrm{mg} \mathrm{L}^{-1}$ ALA + distilled water; (2) ALA, $100 \mathrm{mg} \mathrm{L}^{-1}$ ALA + distilled water; (3) drought, $0 \mathrm{mg} \mathrm{L}^{-1}$ ALA + without distilled water; (4) D + A, $100 \mathrm{mg} \mathrm{L}^{-1}$ ALA + without distilled water. The culture soil was a mixture of organic nutrient soil and vermiculite ratio of $3: 1(\mathrm{v} / \mathrm{v})$, which has a water loss rate of about $10.5 \%$ per day without water supplement. After $6 \mathrm{~d}$ of treatment, the second leaves (leaves immediately below the flag leaves) were collected for chloroplast isolation and proteomic analysis. On this time point, the water content of soil was ranging from 70 to $75 \%$ under normal watering condition, while it was ranging from 30 to $35 \%$ under drought condition. With the purpose of minimizing the deviation between different parallel samples under the same treatment, the sample was retrieved from independent three plots of wheat seedlings. The workflow is shown in Fig. 8.

\section{Physiological measurements}

The stress parameter the wheat seedlings have suffered was evaluated using the soil water potential. The physiological traits were investigated including the leaf osmotic potential, relative water content (RWC), and chlorophyll content. Fresh seedling leaves were sampled from three replicates under each treatment. RWC was calculated by the following formula: RWC $(\%)=(\mathrm{FW}-\mathrm{DW}) /(\mathrm{TW}-$ DW) $\times 100$ [23]. The chlorophyll content was determined by spectrophotometry according to Porra et al. [66]. The leaf osmotic potential was measured using a water potential analyzer (WP4C, Decagon Devices Inc., USA).

\section{Chloroplast isolation}

Pure and intact wheat chloroplasts were isolated from $10 \mathrm{~g}$ of fresh leaves according to Tamburino et al. with modifications [10]. All steps were carried out at $4{ }^{\circ} \mathrm{C}$. Fresh leaves were homogenized thoroughly in $100 \mathrm{~mL}$ of phosphate buffer (pH 7.6) containing $330 \mathrm{mM}$ Dsorbitol, $50 \mathrm{mM}$ Hepes-KOH, $2 \mathrm{mM} \mathrm{MgCl}_{2}, 2 \mathrm{mM}$ EDTA- $\mathrm{Na}_{2}$, and $5 \mathrm{mM}$ ascorbic acid. Homogenates were filtered through 4 layers of filter paper and washed until no green liquid overflowed. The filtrate was centrifuged at $300 \times g$ for $1 \mathrm{~min}$, and the supernatant was centrifuged again at $1000 \times g$ for $2 \mathrm{~min}$. Pellets were resuspended in phosphate buffer ( $\mathrm{pH} 7.6)$ containing $330 \mathrm{mM}$ Dsorbitol, $50 \mathrm{mM}$ Hepes- $\mathrm{KOH}$, and $1 \mathrm{mM}$ DTT. The suspension was carefully loaded onto a contiguous Percoll gradient (Sigma-Aldrich, USA) and centrifuged at $10500 \times g$ for $10 \mathrm{~min}$. Intact chloroplasts were carefully recovered and resuspended in a 5 -fold volume of buffer containing $20 \mathrm{mM}$ Tricine- $\mathrm{KOH}$ (pH 7.6), $5 \mathrm{mM} \mathrm{MgCl}_{2}$, $2.5 \mathrm{mM}$ EDTA, and $0.3 \mathrm{M}$ sorbitol. Organelle purity and intactness were monitored via fluorescence microscopy 

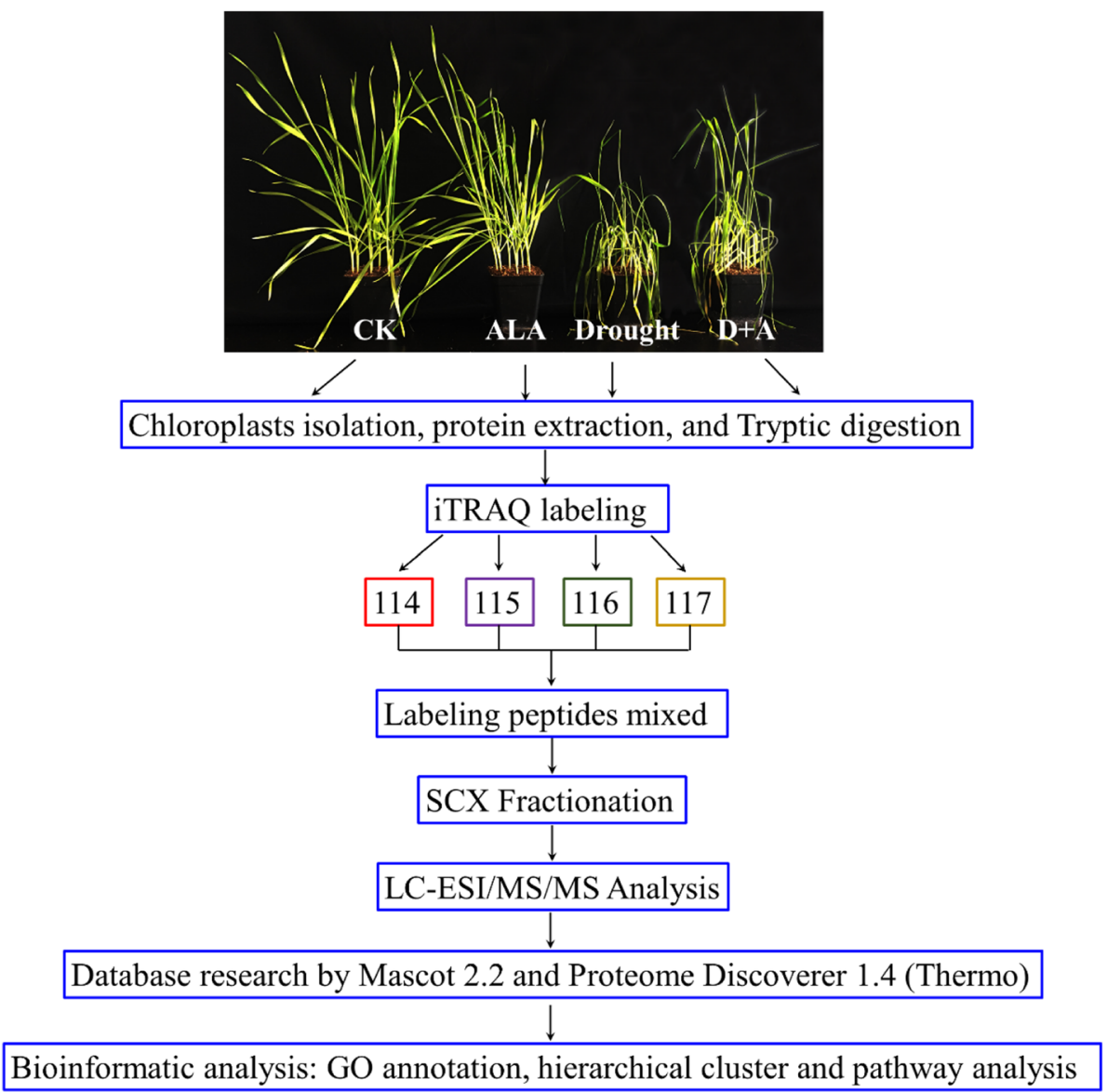

Fig. 8 ITRAQ labeling and LC-MS/MS workflow to identify chloroplast proteins in wheat seedling leaves under drought stress and exogenous ALA pretreatment. CK, treated with $0 \mathrm{mg} \mathrm{L}^{-1} \mathrm{ALA}+$ distilled water; ALA, treated with $100 \mathrm{mg} \mathrm{L}^{-1} \mathrm{ALA}$ and distilled water; drought, treated with $0 \mathrm{mg}$ $\mathrm{L}^{-1}$ ALA without distilled water; $\mathrm{D}+\mathrm{A}$, treated with $100 \mathrm{mg} \mathrm{L}^{-1} \mathrm{ALA}$ without distilled water. The four treatments, CK, ALA, drought, and D+A, were labeled with iTRAQ tags $114,115,116$, and 117, respectively

(Supplementary Figure 3). After centrifugation at $2100 \times g$ for $5 \mathrm{~min}$, the pellets were recovered, quickly frozen in liquid nitrogen, and then stored at $-80^{\circ} \mathrm{C}$ until use. Three biological replicates were used for each treatment condition.

\section{Chloroplast protein extraction and digestion}

The chloroplast protein extraction procedure followed the instructions of the Sigma kit for the isolation of intact chloroplasts from leaves (Sigma, CPISO-1KT). The intact chloroplasts were solubilized in $1 / 10$ volumes of SDT buffer (4\% SDS, $100 \mathrm{mM}$ DTT, and $150 \mathrm{mM}$ Tris$\mathrm{HCl}, \mathrm{pH}$ 8.0). After 3 min of incubation in boiling water, the suspensions were ultrasonicated $(80 \mathrm{w}, 10 \mathrm{~s}$ ultrasonic at a time, every $15 \mathrm{~s}$, and 10 times) and incubated at $100^{\circ} \mathrm{C}$ for $3 \mathrm{~min}$. The crude extract was clarified by centrifugation at $13,000 \times g$ at $25^{\circ} \mathrm{C}$ for $10 \mathrm{~min}$ [67]. The extracted chloroplast proteins were quantitatively determined using the Bradford assay with BCA as a standard, and $20 \mu \mathrm{g}$ of sample was used for the quality verification by an SDS-PAGE analysis. The supernatants were stored at $-80^{\circ} \mathrm{C}$ until use.

Protein digestion was performed according to the filteraided sample preparation (FASP) procedure described by Wisniewski et al. [67]. Two hundred micrograms of each extracted protein was added to $200 \mu \mathrm{L}$ of UA buffer $(\mathrm{pH}$ 8.0) containing $8 \mathrm{M}$ urea and $150 \mathrm{mM}$ Tris- $\mathrm{HCl}$. The mixture was transferred to a $10 \mathrm{kDa}$ ultrafilter centrifuge tube and centrifuged twice at $14,000 \times g$ for $15 \mathrm{~min}$. The sediment was dissolved in $100 \mu \mathrm{L}$ of $50 \mathrm{mM}$ IAA (prepared by UA buffer) and was shaken at $600 \mathrm{rpm}$ for $1 \mathrm{~min}$. After 30 min of incubation in the dark at room temperature, the dissolution was centrifuged at $14,000 \times g$ for $10 \mathrm{~min}$. The sediment was again washed twice using $100 \mu \mathrm{L}$ of UA buffer and then twice washed using $100 \mu \mathrm{L}$ of dissolution buffer $(50 \mathrm{mM}$ triethylammonium bicarbonate, $\mathrm{pH} 8.5)$ by centrifuging the sample at $14,000 \times g$ for $10 \mathrm{~min}$. Then, the proteins were digested in $40 \mu \mathrm{L}$ of trypsin buffer, which 
contained $2 \mu \mathrm{g}$ of trypsin in $40 \mu \mathrm{L}$ of dissolution buffer. The digestion of the chloroplast proteins was performed at $37^{\circ} \mathrm{C}$ for $18 \mathrm{~h}$ with shaking. The digested peptides were collected by centrifugation at $14,000 \times g$ for $10 \mathrm{~min}$, and the sediment was discarded.

\section{iTRAQ labeling and SCX separation}

Eighty micrograms of the peptides were labeled using the iTRAQ Reagent-4Plex Multiplex Kit (AB SCIEX) according to the manufacturer's protocol. The four treatments, CK, ALA, drought, and D + A, were labeled with iTRAQ tags $114,115,116$, and 117 , respectively. The separation of the iTRAQ-labeled peptides by SCX was performed on an AKTA Purifier 100 (GE Healthcare). The iTRAQ-labeled peptides that were prepared as above were mixed, and $10 \times$ volume buffer A $(10 \mathrm{mM}$ $\mathrm{KH}_{2} \mathrm{PO} 4,25 \% \mathrm{v} / \mathrm{v} \mathrm{ACN}, \mathrm{pH}$ was adjusted to 3.0 with phosphoric acid) was added prior to loading the samples onto a polysulfoethyl $4.6 \times 100 \mathrm{~mm}$ SCX $200 \AA$ column containing $5 \mu \mathrm{m}$ particles (PolyLC Inc., Maryland, U.S.A.). The peptides were eluted at a flow rate of $1 \mathrm{ml} /$ min with a gradient of $100 \%$ buffer $\mathrm{A}$ for 25 and 25.01 min, $90 \%$ buffer $\mathrm{A}$ and $10 \%$ buffer $\mathrm{B}\left(10 \mathrm{mM} \mathrm{KH_{2 }} \mathrm{PO}_{4}\right.$ $\mathrm{pH} 3.0,500 \mathrm{mM} \mathrm{KCl}, 25 \% \mathrm{CAN}$ ) for 32 and $32.01 \mathrm{~min}$, $80 \%$ buffer $A$ and $20 \%$ buffer B for 42 and $42.01 \mathrm{~min}$, $55 \%$ buffer $A$ and $45 \%$ buffer B for 47 and $47.01 \mathrm{~min}$, $100 \%$ buffer B for 52 and $60 \mathrm{~min}$, and 100\% buffer A for 60.01 and $75 \mathrm{~min}$. Then, in total, 33 fractions were freeze-dried and desalinized by a $\mathrm{C}_{18}$ cartridge prior to liquid chromatography-mass spectrometry (LC-MS) analysis.

\section{LC-MS analysis}

The peptides of each fraction ( $10 \mu \mathrm{L}$ autoinjections) were separated using an EASY-nLC1000 HPLC system (Thermo Scientific, USA) with a flow rate of $250 \mathrm{~nL} /$ min. The injection column was EASY-column C18 packed with $5 \mu \mathrm{m} \mathrm{C18}$ particles $(2 \mathrm{~cm} \times 100 \mu \mathrm{m}$, Thermo Scientific, Waltham, USA), and the separation column was EASY-column C18 packed with $3 \mu \mathrm{m} \mathrm{C18}$ particles (75 $\mu \mathrm{m} \times 100 \mathrm{~mm}$, Thermo Scientific, USA). The column was prebalanced by $95 \%$ solvent A (water, $0.1 \% \mathrm{v} / \mathrm{v}$ formic acid) and $5 \%$ solvent B (water, $0.1 \% \mathrm{v} / \mathrm{v}$ formic acid and $84 \%$ acetonitrile). Peptides were eluted by the application of a linear gradient mobile phase: a gradient from $0 \%$ solvent B to $35 \%$ solvent B over 55 min, followed by $35 \%$ solvent B to $100 \%$ solvent B over 3 min, which was maintained for 2 min.

A Q-Exactive system (Thermo Finnigan, USA) was applied in the MS analysis of the fractions separated by capillary HPLC. Data were acquired in the positive ESI mode with auto MS/MS in the range of $\mathrm{m} / \mathrm{z} 300-1800$. The parameters of the first level of MS were as follows: 70,000 at $\mathrm{m} / \mathrm{z} 200$ of the resolution level, 3e6 of AGC target, $10 \mathrm{~ms}$ of maximum IT, and $40 \mathrm{~s}$ of dynamic exclusion. The parameters of the second level of MS were as follows: $2 \mathrm{~m} / \mathrm{z}$ of isolation window, 17,500 at m/z 200 of resolution level, $60 \mathrm{~ms}$ of maximum IT, $30 \mathrm{eV}$ of normalized collision energy, $0.1 \%$ of underfill ratio, and the activation type was HCD.

\section{Bioinformatic analysis}

The raw data files of the MS analysis were submitted to the Mascot 2.2 server (Matrix Science, Boston, USA) for relative quantification and protein identification using Proteome Discoverer software (version 1.4; Thermo, USA). The database used for the MS/MS data searching was the UniProt Triticum aestivum protein database, including 145,635 sequences that were released on July 17 , 2017. The false discovery rate (FDR) was calculated and used to filter the effective peptide by the standard of FDR $\leq 0.01$. The detected protein threshold in the software was set to achieve 95\% confidence. The chloroplast proteomic analysis was performed with biological triplicates, and Student's $t$-test was used to evaluate the significance of the DACPs between treatments at the level of $P<0.05$. The iTRAQ ratios between different treatments higher than 1.5 and lower than 0.667 were selected to classify the proteins as up- or downregulated, respectively. PCA was carried out to assess the similarity and difference of chloroplast proteome among the four samples using online visualizing clustering software of ClustVis (https://biit.cs.ut.ee/clustvis/) [68].

The DACPs were functionally categorized according to the Gene Ontology (GO) annotation by BLAST2GO software (https://www.blast2go.com/). The pathways of the DAPs were predicted using the Kyoto Encyclopedia of Genes and Genomes (KEGG) (http://www.kegg.jp/ $\mathrm{kegg} /$ ). The cluster analysis of the DACPs was performed using Cluster 3.0 software (http://bonsai.hgc.jp/ mdehoon/software/cluster/software.htm). Protein-protein interactions (PPIs) were predicted by the Search Tool of the Retrieval of Interaction Genes/Proteins (STRING) database (Version 11.0) [69], and the interaction network was illustrated by Cytoscape software [70]. The PPIs with interaction scores higher than 0.7 (high confidence) were subjected to further interaction network analysis.

\section{RNA extraction and real-time PCR analysis}

Total RNA was extracted from the second leaves and reversely transcribed to cDNA. The cDNA was used for quantitative real-time PCR analysis as previously described [23]. We randomly selected the genes for six differentially accumulated proteins to investigate their relative transcription levels. Primer pairs for qRT-PCR analysis were designed from the corresponding genomic sequences of the targeted proteins using the Primer 5 
software (PREMIER Biosoft International, USA). The amplification of $\beta$-actin was used as an internal control [71]. All the primer sets were listed in Supplementary Table 3. The relative expression levels of specific genes were calculated using the $2^{-\Delta \Delta C T}$ method [72].

\section{Determination of $\mathrm{H}_{2} \mathrm{O}_{2}$ content, $\mathrm{O}_{2}{ }^{-}$production rate, and peroxidase (POD) and glutathione peroxidase (GPX) activities in the chloroplasts}

The $\mathrm{H}_{2} \mathrm{O}_{2}$, content, $\mathrm{O}_{2}{ }^{-}$production rate, and POD (EC 1.11.1.7) and GPX (EC 1.11.1.9) activities in the chloroplasts were determined according to the methods of $\mathrm{Li}$ et al. [73] immediately after the chloroplasts were isolated. The $\mathrm{H}_{2} \mathrm{O}_{2}$ content in the chloroplasts was determined by monitoring the absorbance of the titanium peroxide complex at $410 \mathrm{~nm}$, and the production rate of $\mathrm{O}_{2}{ }^{-}$was measured at an absorbance at $530 \mathrm{~nm}$. The POD activity was determined by recording the changes at $470 \mathrm{~nm}$ during guaiacol oxidation for $4 \mathrm{~min}$, and one enzymatic unit was defined as the change in 1 unit of absorbance per minute. The GPX activity was measured by monitoring the increase in the absorbance at $470 \mathrm{~nm}$ due to the oxidation of guaiacol.

\section{Data analysis}

Three independent replicates were performed for each measurement, and the results are shown as the mean \pm standard deviation (SD). GraphPad Prism 7.0 software (GraphPad software Inc., California, USA) was used for statistical analysis by one-way ANOVA, and the significant differences of the means among treatments were compared using Tukey's multiple comparisons test at a level of $P<0.01$.

\section{Supplementary information}

Supplementary information accompanies this paper at https://doi.org/10. 1186/s12870-020-2297-6

Additional file 1: Supplementary Table 1. The identified peptides in chloroplast extracted from wheat leaves under different treatments.

Additional file 2: Supplementary Table 2. The identified proteins in chloroplast extracted from wheat leaves under different treatments.

Additional file 3: Supplementary Table 3. Primers in the real-time PCR assay.

Additional file 4: Supplementary Figure 1. Principal component analysis of chloroplast proteome of wheat seedling leaves under drought stress and exogenous ALA pretreatment. CK, treated with $0 \mathrm{mg} \mathrm{L}^{-1} \mathrm{ALA}$ + distilled water; ALA, treated with $100 \mathrm{mg} \mathrm{L}^{-1} \mathrm{ALA}$ and distilled water; drought, treated with $0 \mathrm{mg} \mathrm{L}^{-1}$ ALA without distilled water; $\mathrm{D}+\mathrm{A}$, treated with $100 \mathrm{mg} \mathrm{L}^{-1}$ ALA without distilled water. Vector scaling is applied to rows; Nipals PCA is used to calculate principal components. $X$ and $Y$ axis show principal component 1 and principal component 2 that explain 44.4 and $20 \%$ of the total variance, respectively. Prediction ellipses are such that with probability 0.95 , a new observation from the same group will fall inside the ellipse. $N=12$ data points including three independent biological replicates for each treatment.
Additional file 5: Supplementary Figure 2. The correlation of qRTPCR and proteomic analysis for randomly selected DACPS.

Additional file 6: Supplementary Figure 3. The representative fluorescence microscopy images of extracted chloroplast. The chloroplasts were extracted from plants treated with distilled water (a), $100 \mathrm{mg} \mathrm{L}^{-1}$ ALA and distilled water (b), $0 \mathrm{mg} \mathrm{L}^{-1}$ ALA without distilled water (c), and $100 \mathrm{mg} \mathrm{L}^{-1}$ ALA without distilled water (d). The wheat plants underwent drought stress $3 \mathrm{~d}$ after pretreatment with or without ALA.

\section{Abbreviations}

ALA: 5-Aminolevulinic acid; CK: Control; DACPs: Differentially abundant chloroplast proteins; FASP: Filter-aided sample preparation; FDR: False discovery rate; GO: Gene ontology; GPX: Glutathione peroxidase; LCMS: Liquid chromatograph mass spectrometer; POD: Peroxidase; PPIs: Protein-protein interactions; ROS: Reactive oxygen species

\section{Acknowledgements}

We thank Hoogen-bio Co., Ltd., for the technical assistance with the ITRAQ LC-MS/MS analysis.

\section{Authors' contributions}

YW and BS contributed to the experimental design and writing of this manuscript. YW, XL, SW, and JW contributed to the performance of the experiments. BS, NL, and FQ contributed to the data analysis. All authors have read and approved the manuscript.

\section{Funding}

YW wishes to thank the National Natural Science Foundation of China (grant no. U1704103), the China Scholarship Council (201708410311), and the Scitech Innovation Foundation of Henan Agricultural University (grant no. KJCX2016A06), for supporting the research. The funding bodies played no role in the design of the study and collection, analysis, and interpretation of data and in writing the manuscript.

\section{Availability of data and materials}

The datasets supporting the conclusions of this article are included within the article and its additional files. The mass spectrometry proteomic data of this article have been deposited to the ProteomeXchange Consortium via the iProX (Integrated Proteome resources) partner repository with the dataset identifier PXD017528.

Ethics approval and consent to participate Not applicable.

\section{Consent for publication}

Not applicable.

\section{Competing interests}

The authors declare that they have no competing interests.

\section{Author details}

${ }^{1}$ College of Life Sciences, Henan Agricultural University, No. 63, Nongye Rd. Zhengzhou 450002, Henan Province, China. ${ }^{2}$ College of Science, China Agricultural University, Beijing 100193, China. ${ }^{3}$ Department of Pathology, University of Virginia, Charlottesville, VA 22908, USA. ${ }^{4}$ College of Food Science and Technology, Henan Agricultural University, No. 63, Nongye Rd., Zhengzhou 450002, Henan Province, China.

Received: 25 December 2018 Accepted: 20 February 2020

Published online: 04 March 2020

\section{References}

1. Daryanto S, Wang L, Jacinthe P-A. Global synthesis of drought effects on cereal, legume, tuber and root crops production: a review. Agric Water Manag. 2017:179:18-33.

2. Chen YE, Liu WJ, Su YQ, Cui JM, Zhang ZW, Yuan M, Zhang HY, Yuan S. Different response of photosystem $\|$ to short and long-term drought stress in Arabidopsis thaliana. Physiol Plantarum. 2016;158:225-35. 
3. Kosová K, Vítámvás P, Urban MO, Prášil IT, Renaut J. Plant abiotic stress proteomics: the major factors determining alterations in cellular proteome. Front Plant Sci. 2018;9:122.

4. Bi A, Fan J, Hu Z, Wang G, Amombo E, Fu J, Hu T. Differential acclimation of enzymatic antioxidant metabolism and photosystem II photochemistry in tall fescue under drought and heat and the combined stresses. Front Plant Sci. 2016;7:453.

5. Vanlerberghe GC, Martyn GD, Dahal K. Alternative oxidase: a respiratory electron transport chain pathway essential for maintaining photosynthetic performance during drought stress. Physiol Plant. 2016;157:322-37.

6. Ning F, Wang W. The response of chloroplast proteome to abiotic stress. In: Hossain MA, Wani SH, Bhattacharjee S, Burritt DJ, L-SP T, editors. Drought Stress Tolerance in Plants, Vol 2: Molecular and Genetic Perspectives. Cham: Springer International Publishing; 2016. p. 237-49.

7. Moyet L, Salvi D, Tomizioli M, Seigneurin-Berny D, Rolland N. Preparation of membrane fractions (envelope, thylakoids, grana, and stroma lamellae) from Arabidopsis chloroplasts for quantitative proteomic investigations and other studies. In: Mock H-P, Matros A, Witzel K, editors. Plant Membrane Proteomics: Methods and Protocols. New York: Springer New York; 2018. p. 117-36.

8. Demir F, Niedermaier S, Villamor JG, Huesgen PF. Quantitative proteomics in plant protease substrate identification. New Phytol. 2018;218:936-43.

9. Lei R, Du Z, Kong J, Li G, He Y, Qiu Y, Yan J, Zhu S. Blue native/SDS-PAGE and iTRAQ-based chloroplasts proteomics analysis of Nicotiana tabacum leaves infected with $M$ strain of cucumber mosaic virus reveals several proteins involved in chlorosis symptoms. Proteomics. 2018;18:1700359.

10. Tamburino R, Vitale M, Ruggiero A, Sassi M, Sannino L, Arena S, Costa A, Batelli G, Zambrano N, Scaloni A, et al. Chloroplast proteome response to drought stress and recovery in tomato (Solanum lycopersicum L.). BMC Plant Biol. 2017:17:40.

11. Wang L, Pan D, Li J, Tan F, Hoffmann-Benning S, Liang W, Chen W. Proteomic analysis of changes in the Kandelia candel chloroplast proteins reveals pathways associated with salt tolerance. Plant Sci. 2015;231:159-72.

12. Chai Q, Gan Y, Zhao C, Xu H-L, Waskom RM, Niu Y, Siddique KH. Regulated deficit irrigation for crop production under drought stress. A review Agron Sustain Dev. 2016:36:1-21.

13. Phung $\mathrm{TH}$, Jung S. Perturbed porphyrin biosynthesis contributes to differential herbicidal symptoms in photodynamically stressed rice (Oryza sativa) treated with 5-aminolevulinic acid and oxyfluorfen. Pestic Biochem Physiol. 2014;116:103-10.

14. Xiong J-L, Wang H-C, Tan X-Y, Zhang C-L, Naeem MS. 5-aminolevulinic acid improves salt tolerance mediated by regulation of tetrapyrrole and proline metabolism in Brassica napus L. seedlings under $\mathrm{NaCl}$ stress. Plant Physiol Biochem. 2018;124:88-99.

15. Ahmad R, Ali S, Hannan F, Rizwan M, lqbal M, Hassan Z, Akram NA, Maqbool S, Abbas F. Promotive role of 5-aminolevulinic acid on chromium-induced morphological, photosynthetic, and oxidative changes in cauliflower (Brassica oleracea botrytis L.). Environ Sci Pollut Res. 2017;24:8814-24.

16. An Y, Qi L, Wang L. ALA pretreatment improves waterlogging tolerance of fig plants. PLoS One. 2016;11:e0147202.

17. Sheteiwy M, Shen H, Xu J, Guan Y, Song W, Hu J. Seed polyamines metabolism induced by seed priming with spermidine and 5-aminolevulinic acid for chilling tolerance improvement in rice (Oryza sativa L.) seedlings. Environ Exp Bot. 2017;137:58-72.

18. Niu K, Ma X, Liang G, Ma H, Jia Z, Liu W, Yu Q. 5-Aminolevulinic acid modulates antioxidant defense systems and mitigates drought-induced damage in Kentucky bluegrass seedlings. Protoplasma. 2017;254:2083-94.

19. Han RH, Gao GJ, Li ZD, Dong ZX, Guo ZF. Effects of exogenous 5aminolevulinic acid on seed germination of alfalfa (Medicago varia Martyn.) under drought stress. Grassl Sci. 2018;64:100-7.

20. Song J-X, Anjum SA, Zong X-F, Yan R, Wang L, Yang A-J, Ashraf U, Zohaib A, LV J, Zhang $Y$, et al. Combined foliar application of nutrients and 5aminolevulinic acid (ALA) improved drought tolerance in Leymus chinensis by modulating its morpho-physiological characteristics. Crop Pasture Sci. 2017;68:474-82.

21. Akram NA, lqbal M, Muhammad A, Ashraf M, Al-Qurainy F, Shafiq S. Aminolevulinic acid and nitric oxide regulate oxidative defense and secondary metabolisms in canola (Brassica napus L.) under drought stress. Protoplasma. 2018;255:163-74.

22. Kosar F, Akram NA, Ashraf M. Exogenously-applied 5-aminolevulinic acid modulates some key physiological characteristics and antioxidative defense system in spring wheat (Triticum aestivum L.) seedlings under water stress. S Afr J Bot. 2015;96:71-7.

23. Wang Y, Wei S, Wang J, Su X, Suo B, Qin F, Zhao H. Exogenous application of 5 -aminolevulinic acid on wheat seedlings under drought stress enhances the transcription of $p s b A$ and $p s b D$ genes and improves photosynthesis. Braz J Bot. 2018:41:275-85.

24. Al-Thabet S. Promotive effect of 5-aminolevulinic acid on growth and yield of wheat grown under dry conditions. J Agron. 2006;5:45-9.

25. Chen G, Fan PS, Feng WM, Guan AQ, Lu YY, Wan YL. Effects of 5aminolevulinic acid on nitrogen metabolism and ion distribution of watermelon seedlings under salt stress. Russ J Plant Physiol. 2017;64:116-23.

26. Akram NA, Ashraf M. Regulation in plant stress tolerance by a potential plant growth regulator, 5-aminolevulinic acid. J Plant Growth Regul. 2013; 32:663-79.

27. Zhao YY, Yan F, Hu LP, Zhou XT, Zou ZR, Cui LR. Effects of exogenous 5aminolevulinic acid on photosynthesis, stomatal conductance, transpiration rate, and PIP gene expression of tomato seedlings subject to salinity stress. Genet Mol Res. 2015;14:6401-12.

28. Kim T-W, Hwang J-Y, Kim Y-S, Joo S-H, Chang SC, Lee JS, Takatsuto S, Kim SK. Arabidopsis CYP85A2, a cytochrome P450, mediates the baeyer-villiger oxidation of castasterone to brassinolide in brassinosteroid biosynthesis. Plant Cell. 2005;17:2397-412.

29. Fariduddin Q, Yusuf M, Ahmad I, Ahmad A. Brassinosteroids and their role in response of plants to abiotic stresses. Biol Plantarum. 2014;58:9-17.

30. Heyno E, Innocenti G, Lemaire SD, Issakidis-Bourguet E, Krieger-Liszkay A. Putative role of the malate valve enzyme NADP-malate dehydrogenase in $\mathrm{H}_{2} \mathrm{O}_{2}$ signalling in Arabidopsis. Philos Trans R Soc Lond Ser B Biol Sci. 2014;369:20130228.

31. Hebbelmann I, Selinski J, Wehmeyer C, Goss T, Voss I, Mulo P, Kangasjärvi S, Aro E-M, Oelze M-L, Dietz K-J. Multiple strategies to prevent oxidative stress in Arabidopsis plants lacking the malate valve enzyme NADP-malate dehydrogenase. J Exp Bot. 2011;63:1445-59.

32. Dittami SM, Gravot A, Renault D, Goulitquer S, Eggert A, Bouchereau A, Boyen C, Tonon T. Integrative analysis of metabolite and transcript abundance during the short-term response to saline and oxidative stress in the brown alga Ectocarpus siliculosus. Plant Cell Environ. 2011;34:629-42.

33. Johnson X, Steinbeck J, Dent RM, Takahashi H, Richaud P, Ozawa S, HouilleVernes L, Petroutsos D, Rappaport F, Grossman AR, et al. Proton gradient regulation 5-mediated cyclic electron flow under ATP- or redox-limited conditions: a study of DeltaATpase pgr5 and DeltarbcL pgr5 mutants in the green alga Chlamydomonas reinhardtii. Plant Physiol. 2014;165:438-52.

34. Long TA, Okegawa Y, Shikanai T, Schmidt GW, Covert SF. Conserved role of PROTON GRADIENT REGULATION 5 in the regulation of PSI cyclic electron transport. Planta. 2008;228:907

35. Zhu D, Chu W, Wang Y, Yan H, Chen Z, Xiang Y. Genome-wide identification, classification and expression analysis of the serine carboxypeptidase-like protein family in poplar. Physiol Plantarum. 2018;162:333-52.

36. Chiu C-H, Chen G-H, Tzen JTC, Yang C-Y. Molecular identification and characterization of a serine carboxypeptidase-like gene associated with abiotic stress in tea plant, Camellia sinensis (L.). Plant Growth Regul. 2016;79:345-53.

37. Liu $H$, Wang $X$, Zhang $H$, Yang $Y$, Ge $X$, Song F. A rice serine carboxypeptidase-like gene OSBISCPL1 is involved in regulation of defense responses against biotic and oxidative stress. Gene. 2008;420:57-65.

38. Hinnebusch AG, Lorsch JR. The mechanism of eukaryotic translation initiation: new insights and challenges. Cold Spring Harb Perspect Biol. 2012:4:a011544.

39. Nellist CF, Qian W, Jenner CE, Moore JD, Zhang S, Wang X, Briggs WH, Barker GC, Sun R, Walsh JA. Multiple copies of eukaryotic translation initiation factors in Brassica rapa facilitate redundancy, enabling diversification through variation in splicing and broad-spectrum virus resistance. Plant J. 2014;77:261-8.

40. Shopan J, Mou H, Zhang L, Zhang C, Ma W, Walsh JA, Hu Z, Yang J, Zhang M. Eukaryotic translation initiation factor 2B-beta (elF2Bbeta), a new class of plant virus resistance gene. Plant J. 2017;90:929-40.

41. Jackson RJ, Hellen CU, Pestova TV. The mechanism of eukaryotic translation initiation and principles of its regulation. Nat Rev Mol Cell Biol. 2010;11:113-27.

42. Xu X-Y, Ding Z-J, Chen L, Yan J-Y, Li G-X, Zheng S-J. An eukaryotic translation initiation factor, AtelF5A-2, affects cadmium accumulation and sensitivity in Arabidopsis. J Integr Plant Biol. 2015;57:848-58.

43. Foyer $\mathrm{CH}$, Noctor G. Oxidant and antioxidant signalling in plants: a reevaluation of the concept of oxidative stress in a physiological context. Plant Cell Environ. 2005;28:1056-71. 
44. Ki O, Kanematsu S, Asada K. Intra-and extra-cellular localization of "cytosolic" CuZn-superoxide dismutase in spinach leaf and hypocotyl. Plant Cell Physiol. 1996;37:790-9.

45. Maiorino FM, Brigelius-Flohé R, Aumann KD, Roveri A, Schomburg D, Flohé L. [5] Diversity of glutathione peroxidases. In: Methods Enzymol, vol. 252: Academic Press; 1995. p. 38-53.

46. Bela K, Bangash SAK, Riyazuddin CJ. Plant Glutathione Peroxidases: Antioxidant enzymes in plant stress responses and tolerance. In: Hossain MA, Mostofa MG, Diaz-Vivancos P, Burritt DJ, Fujita M, Tran L-SP, editors. Glutathione in Plant Growth, Development, and Stress Tolerance. Cham: Springer International Publishing; 2017. p. 113-26.

47. Bela K, Riyazuddin R, Horváth E, Hurton Á, Gallé Á, Takács Z, Zsigmond L, Szabados L, Tari I, Csiszár J. Comprehensive analysis of antioxidant mechanisms in Arabidopsis glutathione peroxidase-like mutants under saltand osmotic stress reveals organ-specific significance of the AtGPXL's activities. Environ Exp Bot. 2018;150:127-40.

48. Miao Y, Lv D, Wang P, Wang XC, Chen J, Miao C, Song CP. An Arabidopsis glutathione peroxidase functions as both a redox transducer and a scavenger in abscisic acid and drought stress responses. Plant Cell. 2006;18: 2749-66.

49. Yoshimura K, Miyao K, Gaber A, Takeda T, Kanaboshi H, Miyasaka H, Shigeoka S. Enhancement of stress tolerance in transgenic tobacco plants overexpressing Chlamydomonas glutathione peroxidase in chloroplasts or cytosol. Plant J. 2004;37:21-33.

50. Passardi F, Cosio C, Penel C, Dunand C. Peroxidases have more functions than a Swiss army knife. Plant Cell Rep. 2005;24:255-65.

51. Aiamla-Or S, Shigyo M, Ito S, Yamauchi N. Involvement of chloroplast peroxidase on chlorophyll degradation in postharvest broccoli florets and its control by UV-B treatment. Food Chem. 2014;165:224-31.

52. Wang W-B, Kim Y-H, Lee H-S, Kim K-Y, Deng X-P, Kwak S-S. Analysis of antioxidant enzyme activity during germination of alfalfa under salt and drought stresses. Plant Physiol Biochem. 2009;47:570-7.

53. Choi Y, Lee Y, Jeon BW, Staiger CJ, Lee Y. Phosphatidylinositol 3-and 4phosphate modulate actin filament reorganization in guard cells of day flower. Plant Cell Environ. 2008;31:366-77.

54. Ding H, Han Q, Ma D, Hou J, Huang X, Wang C, Xie Y, Kang G, Guo T. Characterizing physiological and proteomic analysis of the action of $\mathrm{H}_{2} \mathrm{~S}$ to mitigate drought stress in young seedling of wheat. Plant Mol Biol Rep. 2018;36:45-57.

55. Yang $Y$, Kwon HB, Peng HP, Shih MC. Stress responses and metabolic regulation of glyceraldehyde-3-phosphate dehydrogenase genes in Arabidopsis. Plant Physiol. 1993;101:209-16.

56. Bustos DM, Bustamante CA, Iglesias AA. Involvement of nonphosphorylating glyceraldehyde-3-phosphate dehydrogenase in response to oxidative stress. J Plant Physiol. 2008;165:456-61.

57. Guo L, Devaiah SP, Narasimhan R, Pan X, Zhang Y, Zhang W, Wang X. Cytosolic glyceraldehyde-3-phosphate dehydrogenases interact with phospholipase Ddelta to transduce hydrogen peroxide signals in the Arabidopsis response to stress. Plant Cell. 2012;24:2200-12.

58. Apel K, Hirt H. Reactive oxygen species: metabolism, oxidative stress, and signal transduction. Annu Rev Plant Biol. 2004;55:373-99.

59. Kim SH, Kim Y-H, Ahn YO, Ahn M-J, Jeong JC, Lee H-S, Kwak S-S. Downregulation of the lycopene -cyclase gene increases carotenoid synthesis via the $\beta$-branch-specific pathway and enhances salt-stress tolerance in sweetpotato transgenic calli. Physiol Plantarum. 2013;147:432-42.

60. Edge R, McGarvey DJ, Truscott TG. The carotenoids as anti-oxidants - a review. J Photochem Photobiol B Biol. 1997;41:189-200.

61. Dong H, Deng Y, Mu J, Lu Q, Wang Y, Xu Y, Chu C, Chong K, Lu C, Zuo J. The Arabidopsis Spontaneous Cell Death1 gene, encoding a ל-carotene desaturase essential for carotenoid biosynthesis, is involved in chloroplast development, photoprotection and retrograde signalling. Cell Res. 2007;17:458.

62. Zhang W, Zhang H, Ning L, Li B, Bao M. Quantitative proteomic analysis provides novel insights into cold stress responses in petunia seedlings. Front Plant Sci. 2016;7:136.

63. Neilson KA, Mariani M, Haynes PA. Quantitative proteomic analysis of coldresponsive proteins in rice. Proteomics. 2011;11:1696-706.

64. Marinov GK, Lynch M. Conservation and divergence of the histone code in nucleomorphs. Biol Direct. 2016;11:18

65. Xue C, Liu S, Chen C, Zhu J, Yang X, Zhou Y, Guo R, Liu X, Gong Z. Global proteome analysis links lysine acetylation to diverse functions in Oryza sativa. Proteomics. 2018;18:1700036.
66. Porra R, Thompson W, Kriedemann P. Determination of accurate extinction coefficients and simultaneous equations for assaying chlorophylls $a$ and $b$ extracted with four different solvents: verification of the concentration of chlorophyll standards by atomic absorption spectroscopy. Biochim Biophy Acta (BBA)-Bioenergetics. 1989;975:384-94.

67. Wiśniewski JR, Zougman A, Nagaraj N, Mann M. Universal sample preparation method for proteome analysis. Nat Meth. 2009;6:359.

68. Metsalu T, Vilo J. ClustVis: a web tool for visualizing clustering of multivariate data using principal component analysis and heatmap. Nucleic Acids Res. 2015;43:W566-70.

69. Szklarczyk D, Franceschini A, Wyder S, Forslund K, Heller D, Huerta-Cepas J, Simonovic M, Roth A, Santos A, Tsafou KP, et al. STRING v10: protein-protein interaction networks, integrated over the tree of life. Nucleic Acids Res. 2015;43:D447-52.

70. Bachman BJ, Venner E, Lua RC, Erdin S, Lichtarge O. ETAscape: analyzing protein networks to predict enzymatic function and substrates in Cytoscape. Bioinformatics. 2012;28:2186-8.

71. Kang GZ, Li GZ, Liu GQ, Xu W, Peng XQ, Wang CY, Zhu YJ, Guo TC. Exogenous salicylic acid enhances wheat drought tolerance by influence on the expression of genes related to ascorbate-glutathione cycle. Biol Plantarum. 2013;57:718-24.

72. Livak KJ, Schmittgen TD. Analysis of relative gene expression data using real-time quantitative PCR and the $2(-$ Delta Delta $C(T)$ ) method. Methods. 2001;25:402-8

73. Li X, Hao C, Zhong J, Liu F, Cai J, Wang X, Zhou Q, Dai T, Cao W, Jiang D. Mechano-stimulated modifications in the chloroplast antioxidant system and proteome changes are associated with cold response in wheat. BMC Plant Biol. 2015;15:219.

\section{Publisher's Note}

Springer Nature remains neutral with regard to jurisdictional claims in published maps and institutional affiliations.

\section{Ready to submit your research? Choose BMC and benefit from:}

- fast, convenient online submission

- thorough peer review by experienced researchers in your field

- rapid publication on acceptance

- support for research data, including large and complex data types

- gold Open Access which fosters wider collaboration and increased citations

- maximum visibility for your research: over $100 \mathrm{M}$ website views per year

At BMC, research is always in progress.

Learn more biomedcentral.com/submissions 